\title{
Describir para planificar: la ficha técnica en la conservación- restauración del patrimonio fotográfico
}

\section{Sara Brancato}

Resumen: Cuando hablamos de la conservación y restauración del patrimonio fotográfico, a menudo, nos referimos a grandes cantidades de artefactos que conforman fondos o colecciones. La tarea de evaluar el estado de conservación general de cierto conjunto, y planificar los tratamientos necesarios para garantizar su conservación a largo plazo, sería muy difícil sin una herramienta fundamental como es la ficha técnica de examen y conservación-restauración.

Con motivo de la documentación y conservación del fondo fotográfico de la Biblioteca de la Facultad de Bellas Artes de la Universidad Complutense de Madrid, se ha creado un modelo la ficha de la que hablaremos en el presente artículo, que toma el ejemplo de la experiencia italiana en el tema de restauración de material fotográfico y, al mismo tiempo, está adaptado a las indicaciones dictadas por el Plan Nacional de Conservación del Patrimonio Fotográfico, con la intención de utilizar un lenguaje lo más normalizado posible, dentro del territorio español.

Palabras clave: fotografía, ficha técnica, documentación, restauración, conservación

\section{Descrever para planear: a ficha técnica sobre a conservação-restauro do património fotográfico}

Resumo: Quando falamos sobre conservação e restauro de património fotográfico, frequentemente nos referimos a grandes quantidades de artefactos que compõem fundos ou coleções. A tarefa de avaliar o estado geral de conservação de um determinado conjunto, e de planear os tratamentos necessários para garantir a sua conservação a longo prazo, seria muito difícil sem uma ferramenta fundamental como a ficha técnica para exame e conservação-restauro.

Por ocasião da documentação e conservação do acervo fotográfico da Biblioteca da Faculdade de Belas-Artes da Universidade Complutense de Madrid, foi elaborada uma maquete, arquivo de que falaremos neste artigo, que toma como exemplo a experiência italiana em matéria de restauro de material fotográfico e, ao mesmo tempo, é adaptada às indicações ditadas pelo Plano Nacional de Conservação do Património Fotográfico, com o intuito de utilizar a linguagem mais padronizada possível em território espanhol.

Palavras-chave: fotografia, ficha técnica, documentação, restauro, conservação

\section{Describe to plan: the technical data sheet on the conservation-restoration of photographic heritage}

Abstract: When we talk about the conservation and restoration of photographic heritage, we often refer to large numbers of artifacts that make up collections. The task of evaluating the general state of conservation of a certain group and planning the necessary treatments to guarantee its long-term conservation would be very difficult without a fundamental tool such as an examination and conservation-restoration sheet.

On the occasion of the documentation and conservation of the photographic collection of the Library of the Faculty of Fine Arts of the Complutense University of Madrid, a model of conservation-restoration file has been devised wich takes an example from the Italian experience about conservation of photographic materials and, at the same time, it is adapted to the indications dictated by the National Plan for the Conservation of Photographic Heritage, with the intention of using language that is more standardized within Spanish territory. 


\section{Introducción}

Planificar las medidas y los tratamientos de conservación del patrimonio fotográfico sería una labor aún más compleja sin una herramienta, tan elemental y fundamental, como es la ficha técnica de conservación-restauración. Gracias a ella, podemos recopilar las informaciones necesarias para poder dar los correctos cuidados a objetos tan delicados, y variados, como lo son los materiales fotográficos, y mantener un registro completo de las intervenciones realizadas. La situación, ya complicada de por sí en razón al gran número de ejemplares a considerar, se puede dificultar, aún más, cuando se trata de objetos que no han sido con anterioridad inventariados y catalogados, o son inéditos.

Este ha sido el caso de las fotografías sobre papel que componen el fondo fotográfico de la Biblioteca de la Facultad de Bellas Artes de la Universidad Complutense de Madrid, que han dado lugar al presente estudio y a la tesis doctoral en curso, dirigida por Alicia Sánchez Ortiz y Luis Castelo Sardina.

El primer grupo de obras que constituye el fondo, fue sacado a la luz en 2015. Aproximadamente un siglo después de que circularan por las clases de la Escuela de Bellas Artes de Madrid, empleadas como material didáctico para la enseñanza de las asignaturas de Teoría del Arte o Perspectiva (Brancato 2018). Ese conjunto fue digitalizado por Luis Castelo, e inventariado por los profesores Juan Miguel Sánchez Vigil y María Olivera Zaldúa, que dieron a conocer por primera vez la entidad de un primer "lote", de 281 fotografías, que años más tarde se verá incrementado con otras piezas.

Al margen de este primer inventario, no había un registro que atestiguara la presencia de este valioso patrimonio fotográfico en la actual Facultad de Bellas Artes. Se hacía necesario subsanar ese vacío documental en dos sentidos: en relación a la identificación de los objetos y en lo que se refiere a la descripción de su estado de conservación.

El propósito del presente estudio, por ende, ha sido encontrar la forma y los medios con los que describir eficazmente un número importante de fotografías; facilitar la planificación de su conservación y restauración; establecer una terminología comprensible para todos los profesionales implicados en su valorización; y compartir, de un modo sencillo, los datos recogidos, basándonos en las exigencias de la misma Biblioteca.

\section{Objetivo de la investigación}

Para alcanzar los propósitos que nos planteaba la situación en la que nos encontrábamos, era preciso idear una ficha técnica bien sopesada y comparada. Ésta se nos muestra ahora como una herramienta extremadamente significativa y necesaria para la preservación del patrimonio fotográfico, pudiendo aunar informaciones relevantes tanto para el restaurador como para el archivista de nuestra institución, $y$, en su última instancia, para el investigador que quiera acercarse a las obras y contribuir a su estudio.

Suadecuada redacción permitecrear un valioso instrumento apto para la gestión física del fondo y, a la vez, contribuir al conocimiento del patrimonio fotográfico (Gasparini 2012: 51), por lo que se definieron las características necesarias para que cumpliera con nuestras expectativas y sirviera de forma adecuada a la descripción de éste y al planteamiento de sus medidas de conservación.

Nos propusimos realizar, a través de un software para la creación de bases de datos, una ficha, dotada de apartados y campos específicos, que permitiese describir el objeto en todas sus partes y niveles; evaluar el estado de conservación y los tratamientos de conservación o restauración, necesarios para garantizar su estabilidad; y que implementara una terminología normalizada, entre aquellas postuladas por el Plan Nacional de Conservación del Patrimonio Fotográfico (Carrión Gútiez 2015a).

También consideramos necesario que diera la posibilidad de ver simultáneamente la imagen del objeto, tanto por el anverso como por el reverso, además de su propio mapa de alteración anejo. Asimismo, queríamos que pudiese reflejar la información de cada espécimen en subapartados de la misma ficha, que fuera fácil de compilar y consultar. Una interfaz intuitiva y agradable haría aún más ágil la incorporación de datos.

El software elegido habría de consentir, desde luego, el volcado de los datos desde una ficha de catalogación que se había creado según las exigencias de la Biblioteca de la Universidad -su principal destinatario-, y, también, ser más asequible para los profesionales de la restauración, de modo que pudiese encontrar una aplicación útil más allá del caso concreto, objeto de la tesis doctoral. Esto es, que pueda servir, más adelante a otros restauradores, ocupados en preservar nuestro patrimonio fotográfico.

Del mismo modo, la ficha ha de permitir la recopilación de toda la información en dos niveles: el particular y el general. De esta forma, nos proporcionaría un conocimiento completo sobre su estado de conservación, pudiéndose así planificar las respectivas medidas de tutela del conjunto, y la extrapolación de datos estadísticos de las medidas tomadas, que podremos agregar al estudio del fondo.

\section{Problema de la investigación}

La dificultad que presentaba la investigación era estructurar inicial, oportuna y eficazmente los campos de la ficha, sin caer en redundancias, utilizando, en la medida de lo posible, el lenguaje normalizado que nos proporciona el Plan Nacional de Conservación del Patrimonio Fotográfico. Asimismo, la transmisión de la información tenía que ser 
cómoda para todo tipo de usuario, así como había de serlo su lectura.

Elegir el software adecuado y la organización de los apartados, constituyó un punto clave del estudio. Sin un atento análisis de las exigencias del restaurador y las posibilidades del programa, no habría sido posible conformar adecuadamente las voces de la ficha ni alcanzar los objetivos propuestos.

La escasez de bibliografía específica sobre el tema, nos llevó a ampliar la búsqueda de información y a tener en cuenta no solo los casos de estudio publicados en el ámbito de la restauración-conservación de material fotográfico, sino también aquellos relativos a su catalogación y, además, de otros ámbitos de la conservación-restauración de patrimonio.

De esta forma, pudimos constatar varios sistemas con los que describir un objeto de interés cultural y sacar partido de los puntos fuertes observados, adaptándolos a nuestro caso y exigencias concretas.

\section{Importancia de la investigación}

Era importante crear una herramienta útil, práctica y sencilla, que permita a los usuarios describir exhaustiva y adecuadamente el material fotográfico, a beneficio de su preservación, y lo era ulteriormente también para nuestros propósitos, de dotar, a la Biblioteca (y a la Universidad) dueña del fondo, de un recurso que facilite el intercambio de información y una comprensión univoca de la terminología recogida, gracias a un lenguaje lo más normalizado posible, que le asegure una clara lectura a profesionales de distintas áreas.

\section{Situación actual del tema}

En los casos que hemos consultado, podemos concluir que para la descripción de los especímenes fotográficos, sobre todo en lo que se refiere a un elevado número de objetos, los restauradores usan varias formas de documentar su trabajo: con tablas creadas a través del software para hojas de cálculo Microsoft ${ }^{\circledast}$ Excel $^{\circledast}$ (García Bustos 2017); con el programa para base de datos Microsoft ${ }^{\circledR}$ Access $^{\circledR}$; y también con FileMaker ${ }^{\circledR} \mathrm{O}$ con FileMaker Pro (Zafarana 2007: 24; Gutiérrez Reyes 2019: 134). En el ámbito académico, con vocación estrechamente educativa, se han utilizado fichas realizadas con programas de creación de texto, como puede ser el famoso Microsoft ${ }^{\circledR}$ Word $^{\circledR}$, y que se han imprimido para facilitar el estudio directo de un número reducido de obras, y guiar con ellas al alumno en la detección de las técnicas fotográficas y de sus deterioros, a lo largo de las actividades formativas.

En Italia, se han realizado varias publicaciones acerca de fichas de documentación relativas a la conservación, a las técnicas de diagnosis, la conservación preventiva y la intervención de material fotográfico. Éstas son el resultado de los estudios guiados por el Istituto Centrale per il Catalogo e la Documentazione (ICCD) y que se han desarrollado para garantizar una documentación muy detallada, transversal y controlada de los bienes fotográficos ${ }^{[1]}$.

De gran importancia para nuestro estudio, ha resultado ser la publicación II restauro della fotografia: materiali fotografici e cinematografici, analogici e digitali, donde Laura Gasparini, responsable de la Fototeca de la Biblioteca Panizzi de Reggio Emilia, nos muestra la scheda di rilevamento e di restauro, una ficha, distinta para positivos y negativos, que permite registrar, por un lado, los datos técnicos y "anagráficos" de una sola obra y, por otro, los tratamientos a realizar. Ésta se configura como una herramienta de fácil uso y gran alcance, sobre todo en la didáctica de la conservación-restauración del patrimonio fotográfico (Gasparini 2012: 53).

Otra gran aportación a la ficha técnica para la conservación del patrimonio fotográfico es la Scheda conservativa Fotografia, un documento elaborado en 2015 por el Gruppo di lavoro per l'indirizzo metodologico nell'ambito delle discipline della conservazione delle collezioni fotografiche $I C C D$, en constante actualización (Matè y Palazzi 2015), y que se configura como un más que válido instrumento para la determinación de cualquier tipo de actuación acerca de ellos: conservación, restauración, manipulación, exposición y puesta en seguridad (Matè y Palazzi 2017).

La experiencia de los restauradores italianos de material fotográfico ha resultado ser, sin duda, determinante para poder entender las posibilidades que nos ofrece una buena descripción de las obras, de las problemáticas que las afectan y de los medios a disposición en el cuidado de éstas. Al mismo tiempo, entender las tendencias en ámbito español ha sido de gran ayuda para enfocar la situación hacia la resolución del problema que nos habíamos planteado al principio de la investigación: documentar, de forma ordenada y controlada, el material fotográfico.

Una fuente de indiscutible referencia a este propósito ha sido el Plan Nacional de Conservación del Patrimonio Fotográfico, donde se expresan las directrices para la preservación de estos bienes, a partir de su documentación.

Empezando por la premisa de que no se menciona una ficha de intervención para material fotográfico, hemos tenido en cuenta las indicaciones relativas a la descripción de fotografías en los archivos estatales. Un sistema de descripción que se menciona es aquel implementado en el Portal de Archivos Españoles PARES, que utiliza la norma ISAD (G) (Carrión Gútiez 2015b: 230-231).

Asimismo, no hemos dejado de lado algunas de las publicaciones fundamentales para el ámbito español y del vecino Portugal. Destacamos aquellas de conservadoresrestauradores de renombre, tales como Ángel María Fuentes de Cía (Fuentes de Cía 1997; 1999; 2012) o Luís Pavão (Pavão 2001). 
A partir de estos conocimientos, hemos planteado la posibilidad de realizar una ficha que se beneficia de la experiencia italiana, pero destinada a los restauradores que operan en ámbito español.

\section{Metodología}

El punto de partida para el desarrollo de la ficha de conservación-restauración de material fotográfico, particularmente centrado en positivos de papel, ha sido la revisión bibliográfica referida a este tema, eligiendo preferentemente el ámbito geográfico italiano y español, por razones inherentes a la formación académica de la autora -la que suscribe-, y a la aplicación de la ficha en el contexto de la tesis doctoral en la Universidad Complutense de Madrid.

Habiendo previamente conocido las exigencias de la sede en la que se custodiaría el fondo fotográfico objeto del estudio, se ha planteado una ficha capaz de recopilar los datos requeridos por el centro, además de tener en cuenta las directrices del Plan de Conservación del Patrimonio Fotográfico en materia de descripción de los especímenes. Otro aspecto de notable importancia ha sido la intención de relacionar la ficha técnica con la ficha de catalogación de material fotográfico, creada expresamente para este fondo, ya que no se disponía de una específica.

Por esta razón, se individuó y utilizó el software ya en uso dentro de la institución, en cuanto habría permitido un más cómodo traslado de la información.

Considerando los campos presentes en el portal PARES, se incluyó su terminología normalizada para algunos de los parámetros determinados para la identificación del espécimen, y que constituyen sus datos "anagráficos" ${ }^{\text {"[2] }}$. Para poder indicar de una forma estándar el autor o el editor, se hizo referencia al Fichero de Autoridades Virtual Internacional (VIAF ${ }^{\oplus}$ : Virtual International Authorities File).

En lo referente al estado de conservación, la normativa considera los valores Bueno, Regulary Malo, asociando varias patologías a éstos últimos dos. Estimamos importante definir el significado de estos términos, para poder hacer una correcta evaluación de su condición, tomando ejemplo de la Normativa F para la Scheda F, elaborada por el Istituto Centrale per il Catalogo e la Documentazione de Roma (Berardi 2016) ${ }^{[3]}$. Por lo tanto, se establecieron los siguientes significados para cada término:

-Bueno: no hay necesidad de restauración o conservación -Regular: legible, pero faltan algunas partes o se ha producido un deterioro

-Malo: faltan piezas relevantes, mala legibilidad, necesidad de restauración

A los valores Regular y Malo, se asocian un total de 23 patologías, para positivos y negativos, con diferentes soportes:

-Acidez

-Amarilleamiento de la imagen

- Cambio de color

- Coloración (cambio de tono original)

- Craquelado de emulsiones y barnices

- Delaminación

-Depósitos

- Descomposición del soporte

- Desprendimiento de la capa de imagen

- Enrollamiento del soporte

- Especulación o espejo de plata

-Estado algodonoso

- Fragilidad

-Manchas

-Microorganismos

-Oxidación/Manchas de óxido

- Óxido-reducción de la plata

-Pérdida de adherencia

-Pérdidas

- Rotura

- Suciedad generalizada

- Distorsión dimensional

-Sulfuración de la imagen (Carrión Gútiez 2015b: 244-245).

Si bien la terminología era normalizada, nos pareció necesario comparar ese listado, con los deterioros referidos en las fichas de conservación italianas ya citadas, para encontrar el modo más práctico y preciso en el que un restaurador pudiera describir el estado de conservación, y, finalmente, los tratamientos de restauración o las medidas de conservación.

Una vez establecidos los campos y la terminología asociada, se procedió con la construcción de la base de datos con el software elegido.

En nuestro caso, el programa informático que mejor se adaptaba a las necesidades de la Biblioteca, era Microsoft ${ }^{\circledR}$ Access $^{\circledast}$, en cuanto a que ya estaba en uso y no les resulta de ninguna forma ajeno. Otro aspecto que tuvimos en cuenta -que va un poco más allá de nuestro proyecto-, era que este tipo de programa es mucho más accesible para un largo número de usuarios, y mucho más difuso que otros programas para bases de datos.

Lejos de plantear un sistema de documentación complejo, como el del Istituto Centrale per il Catalogo e la Documentazione, que cuenta con 53 valores de patologías, y que ha sido fruto de años de trabajo e intercambios entre los mayores expertos de este ámbito, hemos querido inspirarnos en las experiencias italianas, para realizar una herramienta útil, versátil y adaptada al contexto español de la documentación del patrimonio fotográfico.

La ficha, elaborada con estos criterios, fue sometida a unas pruebas para comprobar su correcto funcionamiento y sus límites, con el objetivo de realizar una adecuada valoración del sistema empleado, y utilizar correctamente las 
posibilidades que nos ofrecía el software. La confrontación con la experiencia de especialistas en catalogación y conservación de material fotográfico fue, sin duda, un paso importante para entender la eficacia del sistema, sobre todo en lo referente a los datos identificativos de las fotografías ${ }^{[4]}$.

\section{Resultados}

Ha sido posible elaborar una ficha de conservaciónrestauración de material fotográfico, en la que nos podemos mover fácilmente para describir el objeto en todos sus aspectos, y que cuenta con tres apartados:

1. Datos identificativos y técnicos [figura 1];

2. Estado de conservación [figura 2];

3. Tratamientos [figura 3].

A cada objeto, es posible asociar una imagen de anverso y reverso, en la pantalla relativa a los Datos identificativos y técnicos, además de un mapa de deterioro de las dos caras, en aquella dedicada al Estado de conservación.

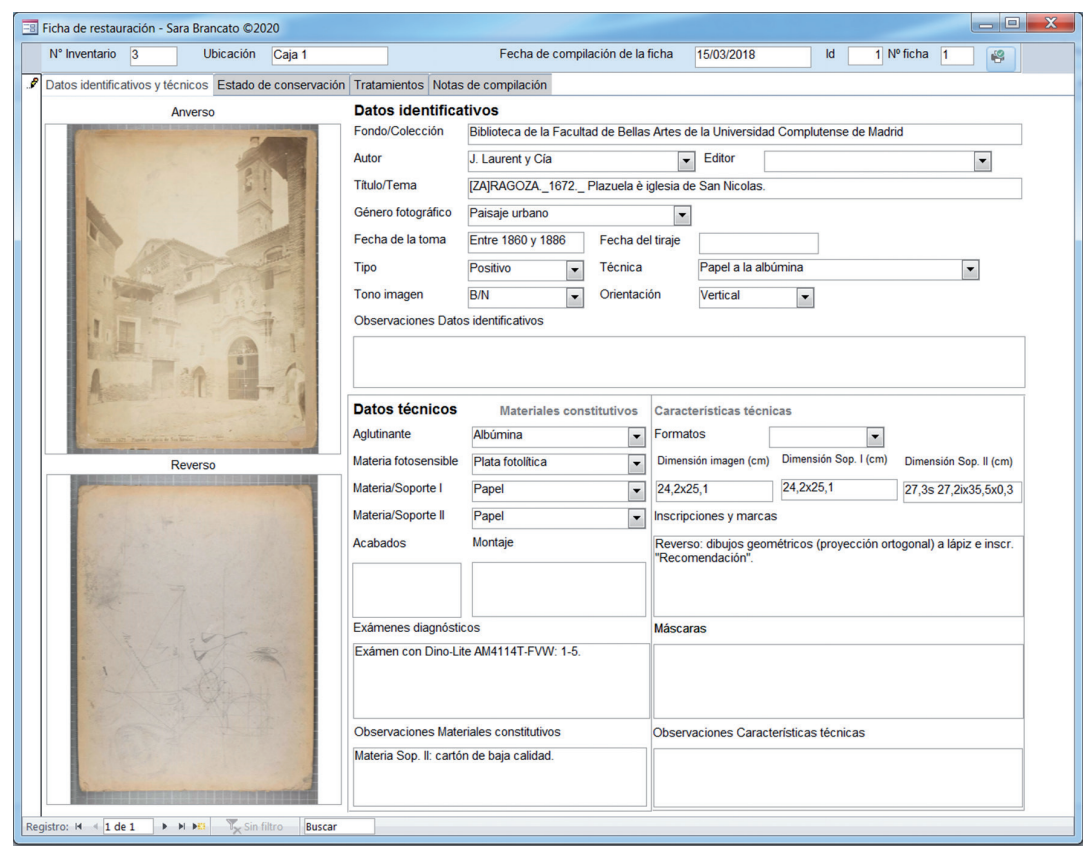

Figura 1.- La ficha de restauración: Datos identificativos y técnicos. Ejemplo de compilación.

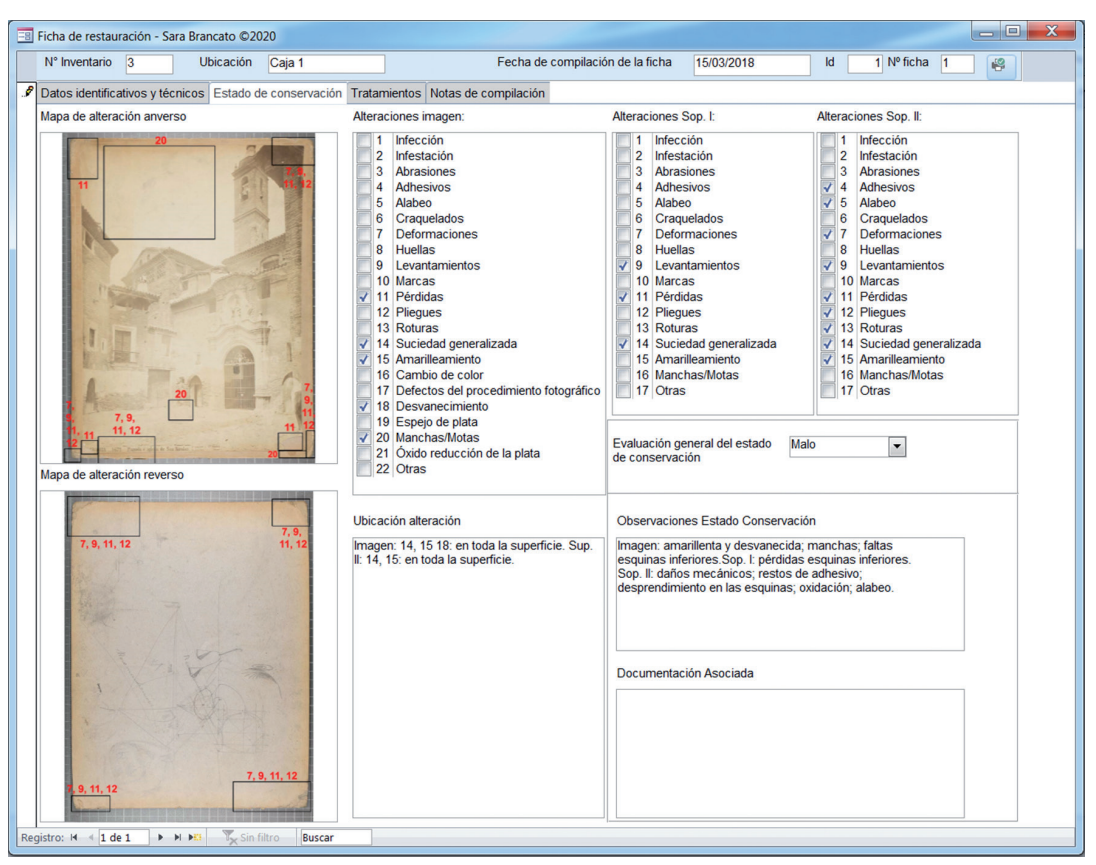

Figura 2.- La ficha de restauración: Estado de conservación. Ejemplo de compilación. 


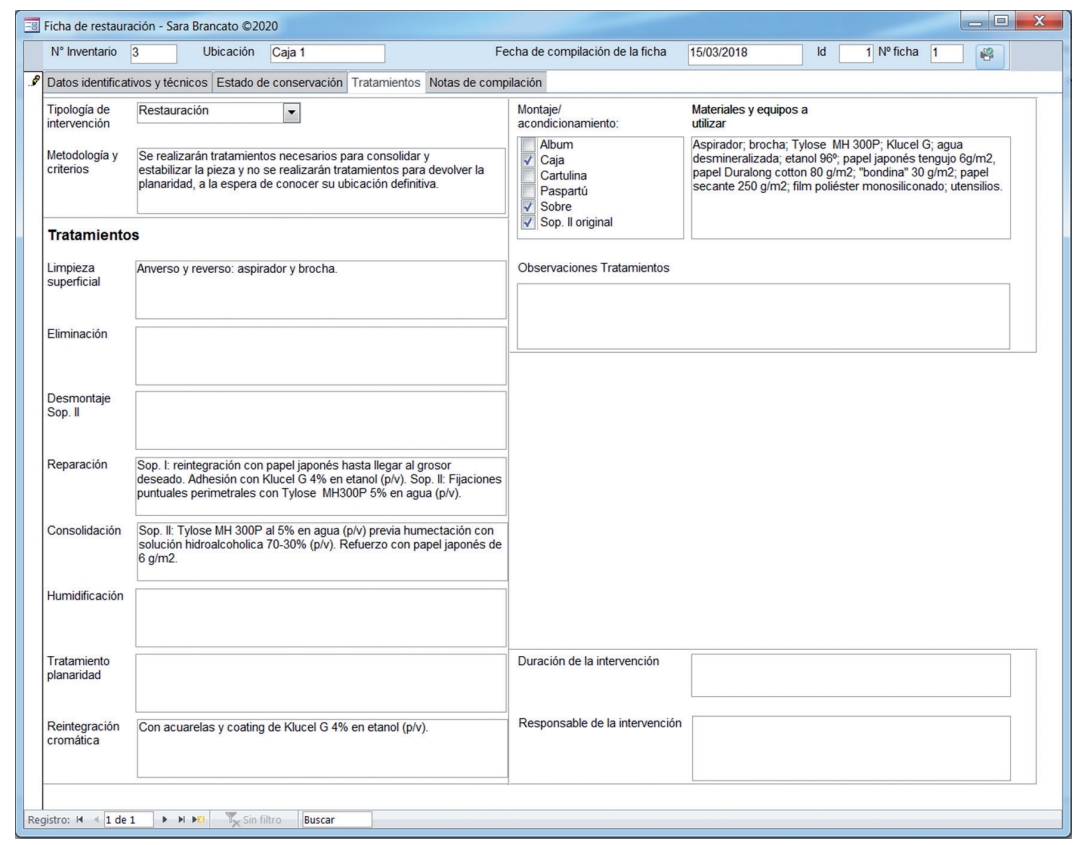

Figura 3.- La ficha de restauración: Tratamientos. Ejemplo de compilación.

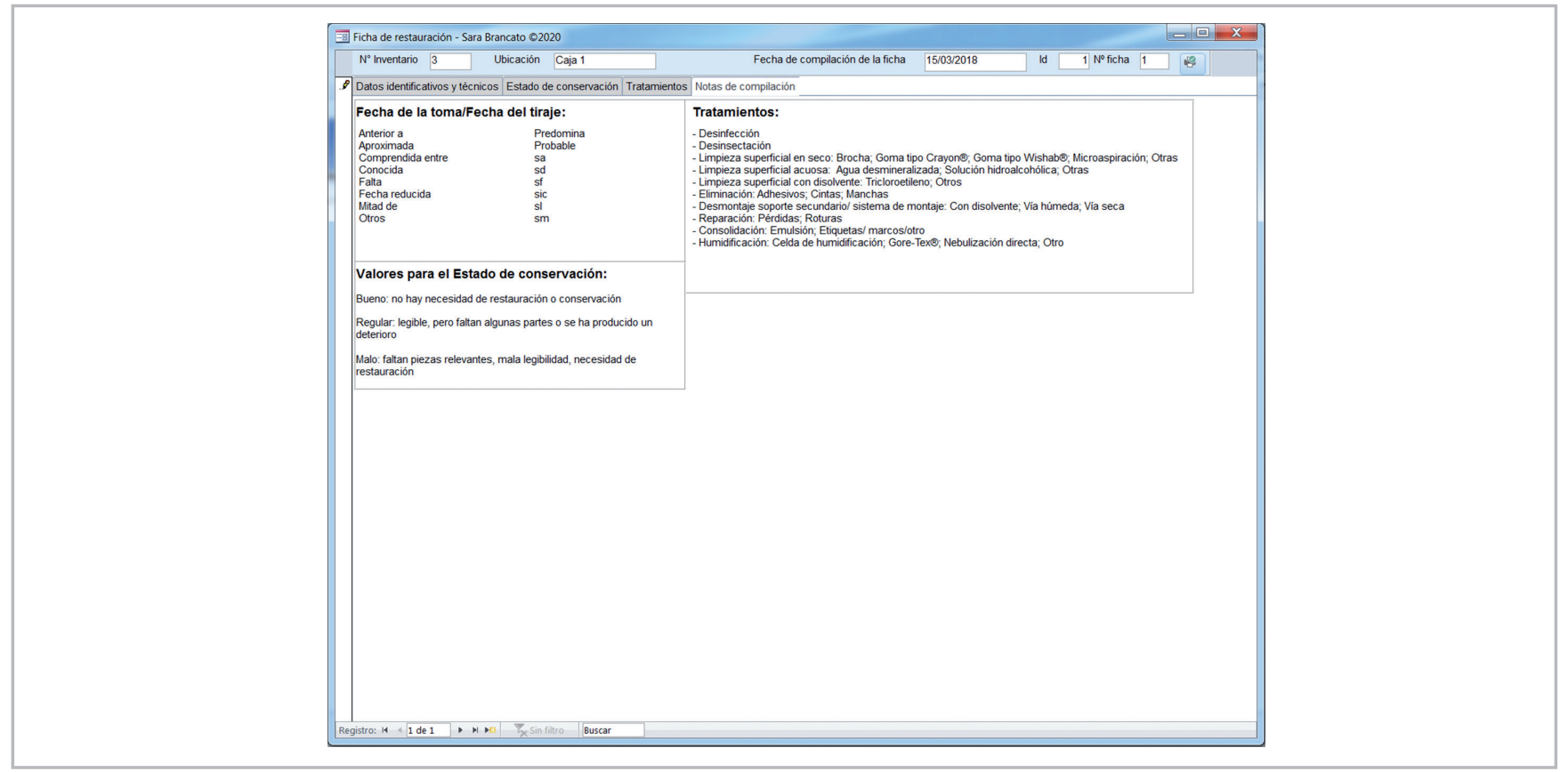

Figura 4.- La ficha de restauración: Notas de compilación. Ejemplo de anotaciones que se pueden añadir para guiar la compilación de la ficha.

Los datos identificativos guardan relación con la ficha de catalogación de referencia y permiten la descripción a través de listas desplegables. Del mismo modo, es posible elegir una opción o más de una, para describir las alteraciones de imagen, soporte primario y soporte secundario.

Considerado el repertorio de deterioros descrito en el Plan de Conservación del Patrimonio Fotográfico, y la necesidad que tenemos los restauradores de sintetizar y adaptar la terminología a una amplia casuística de situaciones, se ha decidido implementar un sistema de organización de la información y unos valores que toman ejemplo de la scheda di rilevamento e di restauro, por permitir describir un amplio espectro de materiales y de sus deterioros, según su origen biológico, físico y químico, dejando en cada sección un campo de libre compilación, para poder introducir aquellas alteraciones no presentes en nuestra lista de 21 deterioros de la imagen y 16 deterioros para los soportes primarios y secundarios: 


\section{ALTERACIONES BIOLÓGICAS: Infección; Infestación.}

ALTERACIONES FÍSICAS: Abrasiones; Adhesivos; Alabeo; Craquelados; Deformaciones; Huellas; Levantamientos; Marcas; Pérdidas; Pliegues; Roturas; Suciedad generalizada.

ALTERACIONES QUÍMICAS: Amarilleamiento; Cambio de color; Defectos del procedimiento fotográfico; Desvanecimiento; Espejo de plata; Manchas/Motas; Óxido reducción de la plata.

En el apartado de los Tratamientos, se han establecido 8 campos libres, donde es posible relatar una amplia gama de intervenciones, y un campo predeterminado, con varias opciones, para indicar el sistema de montaje y acondicionamiento de la obra. También se ha incluido, en esta pantalla, un cuadro en el que mencionar los materiales a utilizar para las intervenciones, la duración y el responsable de la intervención.

En todos los apartados de la ficha hay campos de "Observaciones" donde se permite detallar aquellos aspectos que no ha sido posible describir con los campos ya predispuestos.

Finalmente, se ha contemplado una sección de Notas de compilación [figura 4], para tener siempre presentes los significados de algunos valores, como aquellos que definen el estado de conservación general, o, por ejemplo, los tratamientos, para una más fácil compilación de los campos, en el caso de que se vayan a repetir las operaciones.

\section{Discusión}

Comparando las fichas en hojas de cálculo o en documento de texto, con la ficha elaborada para la intervención en el fondo fotográfico de la Biblioteca de la Facultad de Bellas Artes de la Universidad Complutense de Madrid, hemos podido constatar que ésta última permite organizar de forma más rápida y normalizada en la mayoría de los campos, la información relativa a la identificación, estado de conservación y tratamientos. La interfaz intuitiva permite rellenarla con facilidad y la posibilidad de trasladar los datos a otros formatos, como puede ser el .xlsx, contribuye al análisis de los ejemplares y a la elaboración de otros estudios.

Por esta razón la consideramos como un instrumento completo y eficaz, que, no obstante, conlleva un límite que no podemos obviar, sobre todo cuando vamos a intervenir en un número elevado de ejemplares: la base de datos tiene una capacidad de almacenamiento de información de 2 GB. Incluyendo imágenes muy pesadas, existe el riesgo de sobrecargar la aplicación y provocar incidencias que difícilmente pueden ser reversibles. La precaución que evita estos problemas consiste en cargar imágenes de poco peso, antes de empezar a rellenar la ficha, y así agilizar el trabajo de compilación. Imágenes de alta resolución pueden vincularse de otra forma al documento, por ejemplo, indicando la ruta de su ubicación o creando enlaces al fichero.

\section{Conclusión}

La planificación de las medidas de conservación, y los tratamientos de restauración en materiales fotográficos, es una labor que, a menudo, abarca un gran número de especímenes y que requiere un entendimiento global del estado de conservación, que difícilmente puede ser obtenido sin un instrumento, tan básico como indispensable, como lo es la ficha técnica de conservación-restauración.

El estudio del Fondo fotográfico de la Biblioteca de la Facultad de Bellas Artes de la Universidad Complutense de Madrid, de reciente descubrimiento, nos ha llevado a elaborar un modelo de ficha, que pudiera facilitar el intercambio de información con una ficha de catalogación basada en el lenguaje normalizado, utilizado por la plataforma PARES y descrito en el Plan Nacional de Conservación del Patrimonio Fotográfico. Asimismo, basándonos en la experiencia italiana en documentación, restauración y conservación de patrimonio fotográfico, hemos estructurado, de manera orgánica y ordenada, los tres ámbitos de descripción indispensables para planificar cualquier tipo de actuación, que son: los datos identificativos y técnicos; el estado de conservación; y los tratamientos. Y revisando la terminología inherente a las alteraciones a nivel de imagen, soporte primario y soporte secundario.

De acuerdo con las necesidades de la Biblioteca, hemos elaborado la ficha con un software para bases de datos ya utilizado por ésta, el programa Microsoft ${ }^{\circledast}$ Access ${ }^{\oplus}$, y hemos comprobado que la ficha creada para este caso de estudio concreto podría ser útil para otros materiales fotográficos, por varias razones: además de haberse creado con una interfaz intuitiva y con un lenguaje normalizado en muchos campos de la ficha, esta base de datos se podría compartir fácilmente, ya que se ha creado con un programa muy difundido tanto en ámbito académico como profesional.

Si bien un programa de creación de bases de datos es más complejo de manejar, con respecto a una hoja de cálculo, nos ha permitido conformar una ficha de fácil compilación, donde podemos observar, a primera vista, toda la información contenida en ella, dividida en los tres apartados ya mencionados e incluyendo imágenes y mapas de alteraciones, de consulta, que contribuyen, de manera importante, a respaldar a la descripción del estado de conservación. La posibilidad de traducir la información, así recogida, en otros formatos, permite el análisis de otros aspectos que van más allá de la restauración, como, por ejemplo, puede ser el análisis de datos estadísticos.

Sinánimodedescartarotrostipos de programasinformáticos, se ha querido presentar una ficha ordenada, en muchos casos normalizada, asequible y funcional, para un largo número de usuarios que quieran planificar los tratamientos 
de restauración y las medidas de conservación en materiales fotográficos, teniendo en cuenta los dictámenes del Plan Nacional de Conservación del Patrimonio Fotográfico y las exigencias de los restauradores. Sirva como humilde y sincera contribución nuestros estudios, desvelos y trabajo.

\section{Notas}

[1] Solo para citar algunas: MATĖ, D., SCLOCCHI, M.C. Y COLAPICCHIONI, M. (2008), "Nuovo modello di scheda diagnostica informatizzata per raccolta dati sulle indagini diagnostiche dei documenti fotografici". AFT, rivista di Archivio Fotografico Toscano: 47, 3-10. Prato: Regione Toscana Comune di Prato. ISSN 1120-205X. http://rivista.aft.it/aftriv/controller. jsp?action=rivista view\&rivista id=39. [consulta: 29/01/2021]. MATÈ, D. , PASQUARIELLO, G. , SCLOCCHI, M.C. Y R. SOLURI (2007), "Conservazione preventiva del patrimonio fotografico: metodologie di indagine e scheda diagnostica informatizzata". En Lo Stato dell'Arte 5, V Congresso Nazionale IGIIC, 11-13 ottobre 2007, Cremona. Florencia: Nardini Editore, 363-373, ISBN 978-88-4044156-6.

[2] Por datos "anagráficos" entendemos aquellos que registran la autoría, procedencia, cronología y técnica del espécimen.

[3] Allí nos encontramos con hasta cuatro definiciones para el estado de conservación: Bueno, Discreto, Mediocre y Malo (Berardi 2016: 127).

[4] A tal propósito, agradezco sinceramente por su asesoramiento a Javier Pérez Iglesias y Amelia Valverde González (Biblioteca de la Facultad de Bellas Artes, UCM), Alicia Sánchez Ortiz y Luis Castelo Sardina (Facultad de Bellas Artes, UCM), Juan Miguel Sánchez Vigil (Facultad de Documentación, UCM), Isabel Argerich Fernández, Isabel Lozano de Gregorio y Carlos Teixidor Cadenas (IPCE), Belén Palacios Somoza (BNE).

\section{Referencias}

BERARDI, E. (coord.) (2016). Normativa F - Fotografia- versione 4.00. Strutturazione dei dati e norme di compilazione. Roma: Istituto Centrale per il Catalogo e la Documentazione. http://www. iccdold.beniculturali.it/index.php?it/473/standard-catalografici/ Standard/62. [consulta: 29/01/2021].

BERARDI, E., FRISONI, C., GIUDICI, C. Y SERENA, T. (2016). Normativa FF - Fondi fotografici- versione 4.00. Strutturazione dei dati e norme di compilazione. Roma: Istituto Centrale per il Catalogo e la Documentazione.http://www.iccdold.beniculturali.it/index.php?it/473/ standard-catalografici/Standard/63. [consulta: 29/01/2021].

BERSELLI, S. Y GASPARINI, L. (2004). L' archivio fotografico: manuale per la conservazione e la gestione della fotografia antica e moderna. Bolonia: Zanichelli.

BOADAS, J., ESTEVE CASELLAS, L. Y SUQUE, M. À.. (2001). Manual para la gestión de fondos y colecciones fotográficas. Girona: Centre de Recerca i Difusió de la Imatge (CRDI). Ajuntament de Girona. https://www.girona.cat/sgdap/docs/Manual Fotografia OCR.pdf. [consulta: 29/01/2021].

BRANCATO, S. (2018), “Un patrimonio por descubrir: los fondos fotográficos de la Facultad de Bellas Artes, UCM". En II Jornadas sobre Investigación en Historia de la Fotografía: 1839-1939, un siglo de fotografía: Zaragoza, 25-27 octubre, José Antonio Hernández Latas (dir.), Francisco Javier Lázaro Sebastián (aut.). Zaragoza: IFC, 365-374. ISBN 978-84-9911-509-2. https://ifc.dpz.es/recursos/ publicaciones/37/13/30brancato.pdf [consulta: 29/01/2021].

CARRIÓN GÚTIEZ, A. (coord. Ed.) (2015a). Plan Nacional de Conservación del Patrimonio Fotográfico. Madrid: Ministerio de Educación, Cultura y Deporte, http://www.culturaydeporte. gob.es/planes-nacionales/dam/jcr:e97e9f56-5c1c-4192-96bf3c02fbd6cad3/11-maquetado-patrimonio-fotografico.pdf. [consulta: 29/01/2021].

CARRIÓN GÚTIEZ, A. (coord. Ed.) (2015b). “Anexo 5.8. La descripción del documento fotográfico en los Archivos Estatales" del Plan Nacional de Conservación del Patrimonio Fotográfico. Madrid: Ministerio de Educación, Cultura y Deporte, 230-231, 244-245. http://www.culturaydeporte.gob.es/planes-nacionales/dam/ jcr:1002ecd9-87f2-4bba-91a8-bd9a56060e7d/descripcion-deldocumento-fotografico--en-los-archivos-estatales.pdf. [consulta: 29/01/2021].

CATTANEO, B. (coord.) (2012). II restauro della fotografia: materiali fotografici e cinematografici, analogici e digitali. Florencia: Nardini Editore.

FUENTES DE CÍA, Á. (1997). La identificación de materiales fotográficos convencionales. Madrid: SEDIC. Asociación Española de Documentación e Información.

FUENTES DE CÍA, Á. (2012). La conservación de archivos fotográficos. Documentos de trabajo, octubre - 1a revisión. Madrid: SEDIC. Asociación Española de Documentación e Información. https:// www.sedic.es/wp-content/uploads/2019/06/conservacion-arch.fotograficos.pdf. [consulta: 29/01/2021].

FUENTES DE CÍA, Á. y ROBLEDANO ARILLO, J. (1999). "La identificación y preservación de los materiales fotográficos". En Manual de documentación fotográfica, del Valle, F. (coord.). Madrid: Síntesis, 43-76.

GARCÍA BUSTOS, I. (2017). Medidas de conservación aplicadas al Archivo Fotográfico Hernández Pacheco de la Biblioteca Histórica Marqués de Valdecilla. Trabajo Fin de Máster. Director: Jorge Rivas López-Universidad Complutense de Madrid. 9-11. https://eprints. ucm.es/id/eprint/43905/. [consulta: 29/01/2021].

GASPARINI, L. (2012)."Analisi e raccolta dei dati per la conservazione e per gli interventi di restauro della fotografia". En I/ restauro della fotografia, Cattaneo, B. (coord.) Florencia: Nardini Editore, 51-59.

GUTIÉRREZ REYES, C. (2019), “Restauración del Archivo fotográfico E'42". En Conservación de Arte Contemporáneo, 20a Jornada. 
Madrid: Museo Nacional Centro de Arte Reina Sofía, 129-134. https://www.museoreinasofia.es/publicaciones/conservacionarte-contemporaneo-20a-jornada. [consulta: 29/01/2021].

LAVÉDRINE, B. Y MONOD, S. (2003). A guide to the preventive conservation of photograph collections. Los Angeles: Getty Conservation Institute.

LAVÉDRINE, B., GANDOLFO, J. P. Y MCELHONE, J. (2009). Photographs of the past: process and preservation. Los Angeles: Getty Conservation Institute.

MATÈ, D. Y PALAZZI, D. S. (coord. Ed.) (2015). Scheda conservativa per i documenti fotografici. Roma: ICCD. http://www.iccd.beniculturali. it/getFile.php?id=4072. [consulta: 29/01/2021].

MATĖ, D. Y PALAZZI, D. S. (coord. Ed.) (2017). Scheda conservativa Fotografia. Revisione scheda 2.0. Roma: ICCD. http://www.iccd. beniculturali.it/getFile.php?id=6072. [consulta: 29/01/2021].

MESTRE I VERGÉS, J. (2014). Identificación y conservación de fotografías. Gijón:Trea.

NORRIS, D. H. Y GUTIERREZ, J. J. (2010). Issues in the Conservation of Photographs. Los Angeles: Getty Publications.

OCLC, VIAF ${ }^{\oplus:}$ Virtual International Authorities File. http://viaf.org/. [consulta: 29/01/2021].

PAVÃO, L. (2001). Conservación de colecciones de fotografías. Sevilla: Instituto Andaluz del Patrimonio Histórico.

REILLY, J. M. (1986). Care and identification of 19th-century photographic prints. Rochester: Eastman Kodak Co.

RELLA, L. Y SACCANI, L. (2009), Schede tecniche per il restauratore di dipinti murali, su tela e su tavola. Milán: U. Hoepli.

ROOSA, M. (2002). "Care, handling, and storage of photographs". En International Preservation Issues (IPI) 5. http://www.ifla.org/files/ assets/pac/ipi/ipi5-es.pdf. [consulta: 29/01/2021].

SALVADOR BENÍTEZ, A. (coord.) (2015). Patrimonio fotográfico: de la visibilidad a la gestión. Gijón: Trea.

SCARAMELLA, L. (2003). Fotografia: storia e riconoscimento dei procedimenti fotografici. Roma: Edizioni De Luca.

ZAFARANA, S. (2007), “Un progetto di catalogazione per il Fondo Whitaker". En II Fondo Fotografico Whitaker - Catalogazione e conservazione attraverso la formazione professionale, Mandina, R. (coord.). Palermo: Crimisos Societa' Cooperativa, 22-27. http:// www.crimisos.it/FSE 06/Fondo\%20Fotografico\%20Withaker.pdf. [consulta: 29/01/2021].

\section{Autor/es}

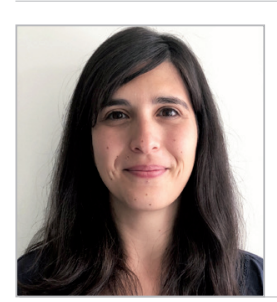

Sara Brancato

sa.brancato@gmail.com

Facultad de Bellas Artes (UCM)

Restauradora de bienes culturales, licenciada en Restauración con especialización en arte contemporáneo (Accademia di Belle Arti di Brera, Italia, 2006-2012). Ha trabajado tanto en el sector público como el privado como colaboradora y como restauradora de obras de arte, en Italia y en España. En 2014 ha sido beneficiaria de la Beca FormARTE otorgada por el Instituto del Patrimonio Cultural de España (Madrid). Desde 2015 es doctoranda en Bellas Artes por la Universidad Complutense de Madrid (UCM), con una tesis sobre historia, conservación, restauración y valorización de los fondos fotográficos de la Facultad de Bellas Artes. https://orcid.org/0000-0002-4038-469X 